\title{
Metabolic effects of newly synthesized phosphodiesterase-3 inhibitor 6-[4-(4- methylpiperidin-1-yl)-4-oxobutoxy]-4- methylquinolin-2(1H)-one on rat adipocytes
}

\author{
Bagher Alinejad', Reza Shafiee-Nick ${ }^{1,2^{*}}$, Hamid Sadeghian ${ }^{3}$ and Ahmad Ghorbani ${ }^{2}$
}

\begin{abstract}
Background: Clinical use of selective PDE3 inhibitors as cardiotonic agents is limited because of their chronotropic and lipolytic side effects. In our previous work, we synthesized a new PDE3 inhibitor named MC2 (6-[4-(4-methylpiperidin-1-yl)-4-oxobutoxy]-4-methylquinolin-2(1H)-one) which produced a high positive inotropic action with a negative chronotropic effect. This work was done to evaluate the effects of MC2 on adipocytes and compare its effects with those of amrinone and cilostamide.

Methods: Preadipocytes were isolated from rat adipose tissue and differentiated to adipocyte in the presence of cilostamide, amrinone or MC2. Lipolysis and adipogenesis was evaluated by measuring glycerol level and Oil Red O staining, respectively. Adipocyte proliferation and apoptosis were determined with MTT assay and Annexin V/PI staining, respectively.

Results: Differentiation to adipocyte was induced by amrinone but not by cilostamide or MC2. Basal and isoproterenol-stimulated lipolysis significantly increased by cilostamide $(p<0.05)$. Similarly, amrinone enhanced the stimulated lipolysis $(p<0.01)$. On the other hand, MC2 significantly decreased both adipogenesis $(p<0.05)$ and stimulated lipolysis $(p<0.001)$. Also, incubation of differentiated adipocytes with MC2 caused the loss of cell viability, which was associated with the elevation in apoptotic rate $(p<0.05)$.

Conclusion: Our data indicate that selective PDE3 inhibitors produce differential effects on adipogenesis and lipolysis. MC2 has proapoptotic and antilipolytic effects on adipocytes and does not stimulate adipogenesis. Therefore, in comparison with the clinically available selective PDE3 inhibitors, MC2 has lowest metabolic side effects and might be a good candidate for treatment of congestive heart failure.
\end{abstract}

Keywords: Adipogenesis, Amrinone, Cilostamide, Lipolysis, Phosphodiesterases

\section{Introduction}

Cyclic nucleotide phosphodiesterases (PDEs) control the level of intracellular cAMP and cGMP, and hence play important roles in cellular signaling pathways. The PDEs are grouped into 11 families which differ in their physiochemical properties, substrate specificities, tissue distributions, and regulatory mechanisms [1]. Among

\footnotetext{
* Correspondence: Shafieer@mums.ac.ir

'Department of Pharmacology, School of Medicine, Mashhad University of Medical Sciences, Mashhad, Iran

${ }^{2}$ Pharmacological Research Center of Medicinal Plants, School of Medicine, Mashhad University of Medical Sciences, Mashhad, Iran

Full list of author information is available at the end of the article
}

them PDE3 has high expression in heart, airway, liver, pancreas, and adipose tissue and involves in the regulation of cardiovascular functions, insulin secretion, and lipid metabolism [2-5]. Selective PDE3 inhibitors have vasodilatory, antithrombotic, antiproliferative, bronchodilatory, anti-inflammatory, and positive inotropic effects [6-8]. A number of PDE3 inhibitors including cilostamide, cilostazol, milirinone, and amrinone were developed to treat patients with heart failure. However, chronic treatment with these agents was associated with some life-threatening side effects, arrhythmia in particular [7-10]. Therefore, designing new PDE3 inhibitors with 
desired pharmacological properties and lesser side effects is an attractive subject.

In the previous works we synthesized novel analogs of cilostamide as selective PDE3 inhibitors and evaluated their cardiac and metabolic properties. One of the test compounds, named MC2 (6-[4-(4-methylpiperidin-1-yl)4-oxobutoxy]-4-methylquinolin-2(1H)-one), produced a potent inotropic action without unwanted effect on basal contraction rate [11-14]. Therefore, it may be a candidate for use as a PDE inhibitor in patients with cardiovascular diseases.

However, in adipose tissue, PDE3 inhibitors increase intracellular cAMP level and thereby increases lipolysis in adipocytes and enhance adipogenesis in preadipocytes $[15,16]$. Dysregulation of lipid metabolism in adipose tissue may cause deleterious consequences in some pathological conditions such as diabetes mellitus, insulin resistance, fatty liver, and obesity [17-19]. Therefore, as a selective PDE3 inhibitor, MC2 is expected to produce some effects on lipid metabolism which could be a potential risk factor for clinical adverse effect.

Therefore, in the present work, we evaluated the effects of $\mathrm{MC} 2$ on adipose tissue functions including adipogenesis and lipolysis, and also on adipocyte viability and apoptosis. Furthermore, the effects of MC2 were compared with the effects of amrinone and cilostamide on adipose tissue.

\section{Materials and method}

\section{Chemicals and reagents}

Isoproterenol, free glycerol reagent, 4-(2-hydroxyethyl) piperazine-1-ethanesulfonic acid sodium salt (HEPES), 4, 5-Dimethylthiazol-2-yl, 2, 5-diphenyl tetrazolium (MTT), fatty acid-free bovine serum albumin (BSA), and collagenase were purchased from Sigma (USA). Dimethyl sulfoxide (DMSO) and 3-isobutyl-1-methylxanthine (IBMX) were provided from Fluka (Buchs, Switzerland). Dulbecco's modified eagle's medium (DMEM), fetal bovine serum (FBS), penicillin/streptomycin, and Annexin V/PI apoptosis kit were obtained from Invitrogen (USA). Indomethacin, dexamethasone, and insulin were kindly provided by EXIR Company (Iran).

The test compound, $\mathrm{MC2}$, was synthesized based on cilostamide structure by Department of Organic Chemistry, Mashhad University of Medical Sciences (Mashhad, Iran) according to the procedure reported by Sadeghian et al. and its PDE3 inhibitory action was assessed by Bioscience Company (BPS Bioscience Inc, San Diego, United States) using PDE assay Kit as described in previous works $[14,20]$. Figure 1 shows the IC50 of cilostamide, amrinone, and MC2 for PDE3. All the phosphodiesterase inhibitors were dissolved in dimethyl sulfoxide (DMSO) at a final concentration of $0.1 \%$ in the medium and equal amounts of carrier were added to control groups of the cells.

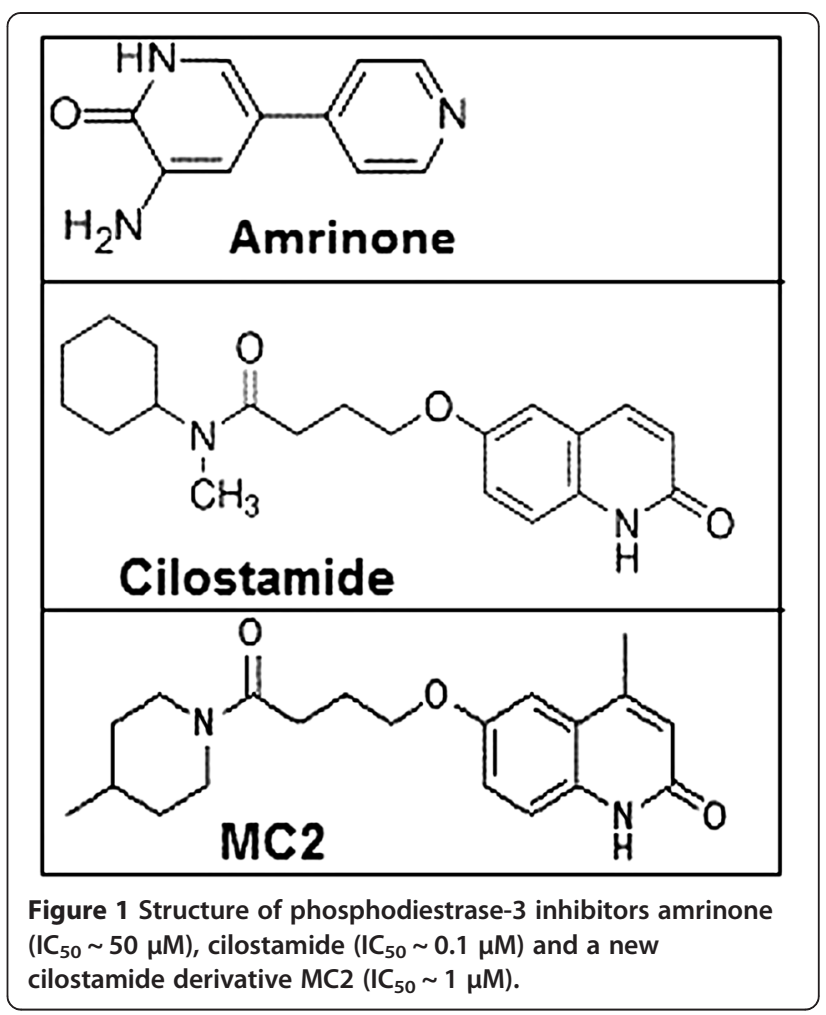

Animals

Adult male Wistar rats with weights of 280-300 g were obtained from Laboratory Animal House, Mashhad University of Medical School, Iran. They were housed under a $12 / 12 \mathrm{~h}$ light/dark daily cycle at $22^{\circ} \mathrm{C}$ and had free access to standard foods and water. All experiments were conducted in accordance with standard ethical guidelines and approved by the local ethics committee of Mashhad University of Medical Sciences.

\section{Preadipocyte preparation and culture}

The animals were sacrificed under ether anesthesia and retroperitoneal fat pads were removed immediately and placed in phosphate-buffered saline (PBS) supplemented with $100 \mathrm{U} / \mathrm{ml}$ penicillin and $100 \mu \mathrm{g} / \mathrm{ml}$ streptomycin in sterile condition. The tissue was minced into small pieces and incubated for $40 \mathrm{~min}$ in PBS containing $2 \mathrm{mg} / \mathrm{ml}$ collagenase at $37^{\circ} \mathrm{C}$ with mild agitation [21,22]. After centrifuging, the floated adipocytes were discarded and the stromal cells were suspended in DMEM medium supplemented with $10 \%$ fetal bovine serum, $100 \mathrm{U} / \mathrm{ml}$ penicillin and $100 \mu \mathrm{g} / \mathrm{ml}$ streptomycin and cultured in flask. After passage 3, the cells were seeded (at a density of 60000 cells $/ \mathrm{cm}^{2}$ ) in 12-well plates. On next day, adipogenesis was induced by applying "induction medium" containing DMEM supplemented with $200 \mathrm{nM}$ insulin, $250 \mu \mathrm{M}$ IBMX, $1 \mu \mathrm{M}$ dexamethasone, $200 \mu \mathrm{M}$ indomethacin and 3\% FBS. On day 3, the cells were subsequently cultured in "maintenance medium" (induction 


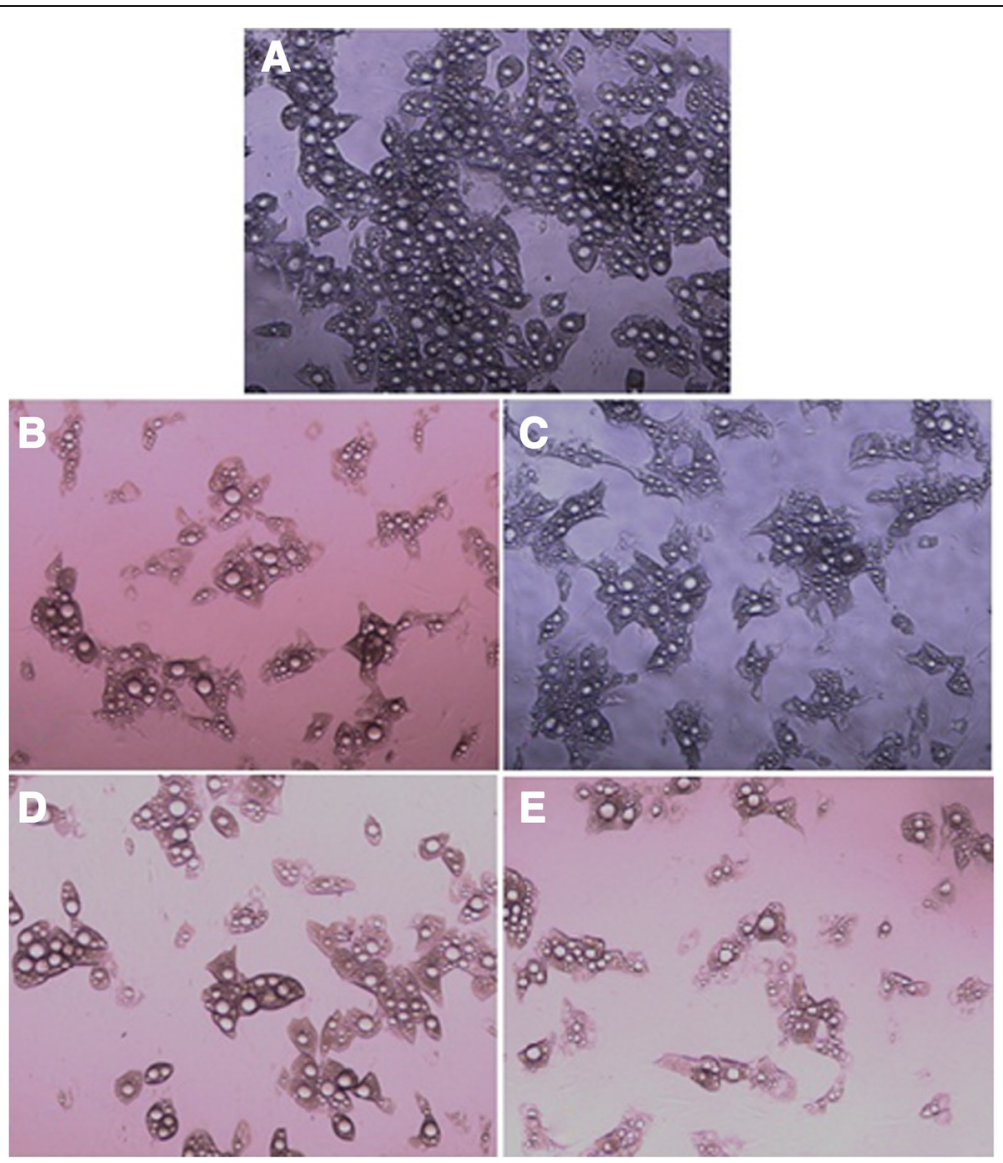

Figure 2 Differentiation of preadipocyte to adipocyte in the presence of (A) IBMX, (B) no PDE inhibitor, (C) amrinone, (D) cilostamide and (E) MC2. Adipogenesis was induced by 3 days incubation in "induction medium"; DMEM supplemented with $3 \%$ fetal bovine serum, $200 \mathrm{nM}$ insulin, $250 \mu \mathrm{M}$ of mentioned PDE inhibitors, $1 \mu \mathrm{M}$ dexamethasone, $200 \mu \mathrm{M}$ indomethacin. Then, the cells were subsequently cultured for 6 days in "maintenance medium" (induction medium without phosphodiestrase inhibitors and indomethacin). Magnification: $\times 100$

medium without IBMX and indomethacin) for 9 days and the medium was changed every 3 days.

To investigate the effect of PDE inhibitors on adipogenesis, IBMX was replaced with the same concentration of amrinone, cilostamide, or MC2 in the induction medium during the first three days of incubation. The cellular triglyceride accumulation was measured as an index of the adipocyte differentiation in the presence of PDE3 inhibitors and compared with IBMX.

\section{Oil Red O staining}

Oil Red $\mathrm{O}$ was used to stain intracellular triglyceride droplets in differentiated adipocytes. Briefly, the cells were washed twice with PBS and fixed with 10\% formalin for $30 \mathrm{~min}$. After an additional washing with PBS, the cells were incubated with Oil Red O solution for 20 min $[21,23]$. Excess stain was removed by washing with distilled water and the stained cells were photographed. Lipid and Oil Red $\mathrm{O}$ were extracted using isopropyl alcohol and absorbance was measured using a spectrophotometer at a wavelength of $545 \mathrm{~nm}$. The lipid content for each experimental group is expressed relative to that of IBMX-differentiated cells (adjusted to 100\%).

\section{Determination of triglyceride}

To support Oil Red O staining, the level of intracellular triglyceride (TG) was evaluated in differentiated adipocytes. Following washing the cells with PBS, intracellular TG was dissolved in $200 \mu \mathrm{l}$ of $1 \%$ Triton X-100/PBS solution. Then, the level of TG was determined by TG assay kit (Pars azma, Co., Ltd., Iran). The protein concentrations were also measured by Bio-Rad protein assay dye reagent (Bio-Rad Laboratories, Inc.). Then the level of TG was normalized to cellular protein content of each treatment group [24]. The $\mathrm{TG} /$ protein content $(\mathrm{mg} / \mathrm{mg})$ was expressed as percentage compared to IBMX treated group as a control.

\section{Cell proliferation assay}

To investigate the effects of the PDE inhibitors on adipocyte proliferation, preadipocytes were seeded $\left(10^{4}\right.$ cell/well $)$ in flat-bottomed 96-well culture plates. After differentiation, adipocytes were incubated with amrinone, cilostamide and 
MC2 at the various concentrations $(10,100$ and $500 \mu \mathrm{M})$ for 6,12 and $24 \mathrm{~h}$. After completion of the treatment, the cells were incubated with MTT solution for $3 \mathrm{~h}$ at $37^{\circ} \mathrm{C}$. The supernatants were aspirated, DMSO was added to each well, and the plates were agitated to dissolve the crystal product [25-27]. Absorbance was measured at $545 \mathrm{~nm}$ (630 $\mathrm{nm}$ as a reference) using a StatFAX303 plate reader.

\section{Annexin V/PI double staining analysis}

To detect the apoptosis induced by PDE inhibitors, Annexin V/PI double staining and flow cytometry analysis were used [28]. After adipocyte differentiation in 12-well plates, the cells were exposed to 10,100 and $500 \mu \mathrm{M}$ of $\mathrm{MC} 2$ for $24 \mathrm{~h}$. After treatment, the cells were washed twice with cold PBS and resuspended in $100 \mu \mathrm{l}$ binding buffer at a concentration of $1 \times 10^{6}$ cells $/ \mathrm{ml}$. Then, $5 \mu \mathrm{l}$ Annexin V-FITC and $10 \mu \mathrm{l} \mathrm{PI}(1 \mathrm{mg} / \mathrm{ml})$ were added to these cells according to manufacturer's instructions. Finally, the cells were analyzed with a FACScalibur flow cytometer (Becton Dickinson) and the distribution of normal, apoptotic and necrotic cells was calculated using WinMDI 2.7 software.

\section{Lipolysis assay}

The differentiated adipocytes (cultured in 12-well culture plates) were pre-incubated with serum-free DMEM for $3 \mathrm{~h}$ and then bathed with $1 \mathrm{ml}$ Krebs-Ringer bicarbonate buffer containing $5.5 \mathrm{mM}$ glucose, $25 \mathrm{mM}$ HEPES and $2 \%(\mathrm{w} / \mathrm{v})$ bovine serum albumin. The cells were left untreated (basal lipolysis) or treated with isoproterenol (stimulated lipolysis) and incubated in the absence or presence of PDE inhibitors at $37^{\circ} \mathrm{C}$ in a humidified chamber under constant shaking for $2 \mathrm{~h}$. Glycerol release in the medium was measured as index of lipolysis using the free glycerol determination kit $[29,30]$.

\section{Statistical analysis}

The results are presented as the mean \pm standard error. The values were compared using the one-way analysis of variances followed by Dunnett's post hoc test. The results were considered to be statistically significant, if the p-value was less than 0.05 .

\section{Results}

\section{Effect of PDE inhibitors on adipogenesis}

The absence of IBMX in culture medium significantly decreased preadipocyte differentiation to adipocyte comparing to the control medium containing IBMX. Also, the level of adipogenesis in cilostamide and MC2 containing medium was lower than that of control medium. However, the effect of amrinone on preadipocyte differentiation was more than cilostamide and $\mathrm{MC} 2$, close to that of IBMX (Figure 2).
Oil Red $\mathrm{O}$ staining showed that in the presence of cilostamide and MC2 the level of lipid droplet accumulation was $69 \pm 6 \%$ and $46 \pm 4 \%$, respectively, which was significantly lower than control medium containing IBMX $(100 \pm 4 \%, \mathrm{p}<0.01-\mathrm{p}<0.001)$ (Figure $3 \mathrm{~A})$. These findings were confirmed by measurement of intracellular TG in the differentiated adipocytes. As shown in Figure 3B, the level of intracellular TG in the presence of cilostamide ( $78 \pm 6$, $\mathrm{P}<0.05)$ and $\mathrm{MC} 2(43 \pm 5, \mathrm{P}<0.001)$ was lower than that of IBMX treated cells $(100 \pm 10)$.

\section{Effect of PDE inhibitors on adipocyte proliferation}

Incubation of differentiated adipocytes with $10-500 \mu \mathrm{M}$ of cilostamide, $10-500 \mu \mathrm{M}$ of amrinoe and $10-100 \mu \mathrm{M}$

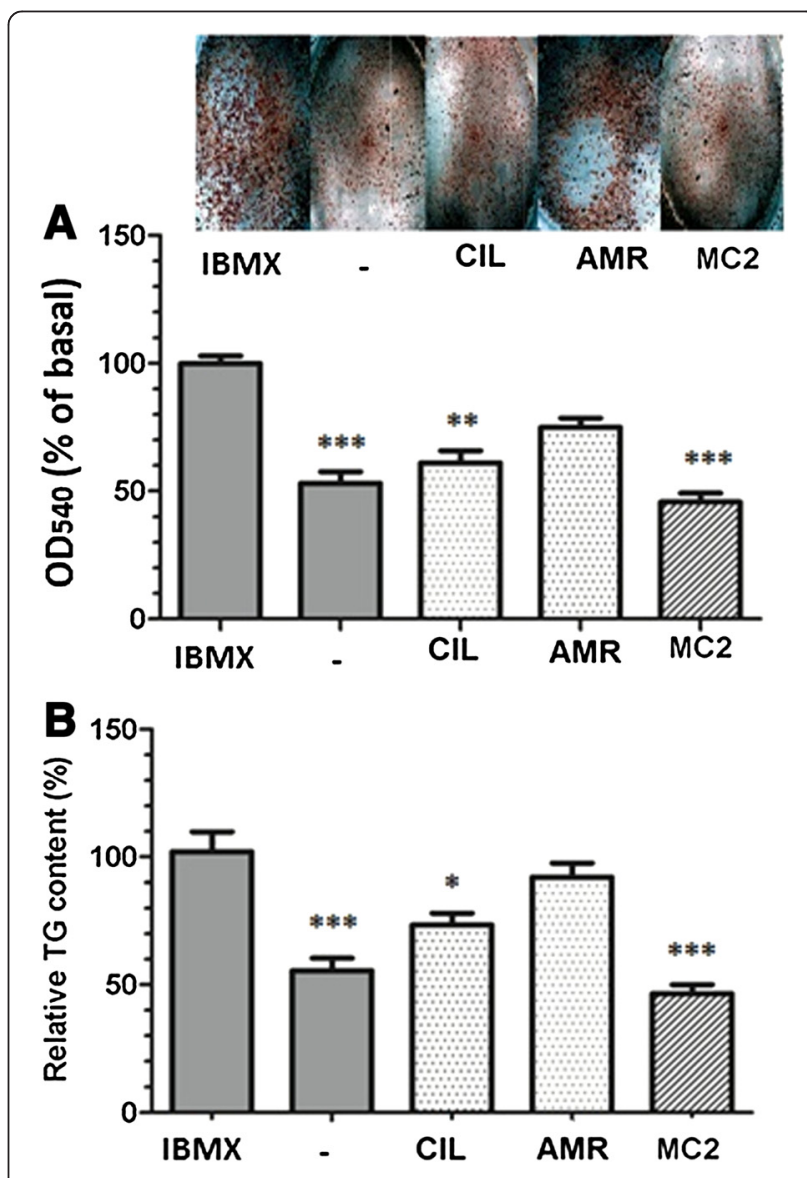

Figure 3 Effects of phosphodiestrase inhibitors on adipogenesis. Differentiation of preadipocytes was induced by 3 days incubation in induction medium; DMEM supplemented with $3 \%$ fetal bovine serum, $200 \mathrm{nM}$ insulin, $1 \mu \mathrm{M}$ dexamethasone, $200 \mu \mathrm{M}$ indomethacin and $250 \mu \mathrm{M}$ phosphodiestrase inhibitors (IBMX, amrinone (AMR), cilostamide (CIL), and (MC2). Then, the cells were subsequently cultured for 6 days in "maintenance medium" (induction medium without PDE inhibitors and indomethacin). Lipid accumulation was estimated by measuring the optical density (OD) of Oil Red O stain (A) or the level of triglyceride (TG) eluted from adipocytes (B). Data are mean \pm SEM of three independent experiments performed in triplicate. ${ }^{*} \mathrm{p}<0.05,{ }^{* *} \mathrm{p}<0.01$ and ${ }^{* * *} \mathrm{p}<0.001$ vs control (IBMX). 
of MC2 had no effect on their proliferation after 6, 12 and $24 \mathrm{~h}$ (Figure 4). MC2 at $500 \mu \mathrm{M}$ significantly decreased proliferation of differentiated adipocyte to $86 \pm 6$ $(\mathrm{p}<0.05), 82 \pm 3(\mathrm{p}<0.01)$ and $79 \pm 6(\mathrm{p}<0.01)$ after 6 , 12 and $24 \mathrm{~h}$, respectively.

\section{Effect of MC2 on adipocyte apoptosis}

Figure 5A shows the results of bivariate Annexin V/PI flow cytometry of differentiated adipocyte after $24 \mathrm{~h}$ incubation with MC2. The lower left quadrant of the histograms shows the viable cells, which exclude PI and are negative for FITC-Annexin V binding. The upper right quadrant represents the early apoptotic cells, which are PI negative and Annexin $\mathrm{V}$ positive, indicating integrity of the cytoplasmic membrane. The lower right quadrant represents the non-viable necrotic and late-stage apoptotic cells, which are positive for Annexin $\mathrm{V}$ binding and PI uptake. As shown in Figure 5B, incubation of differentiated adipocytes with $\mathrm{MC} 2$ caused the loss of cell viability at concentrations of $100 \mu \mathrm{M}(\mathrm{p}<0.05)$ and $500 \mu \mathrm{M}$ $(\mathrm{p}<0.05)$. This effect was associated with the elevation in the number of apoptotic (concentrations of 10 and $100 \mu \mathrm{M}, \mathrm{p}<0.05$ ) and necrotic (concentrations of $500 \mu \mathrm{M}, \mathrm{p}<0.01)$ cells.

\section{Effect of PDE inhibitors on lipolysis}

The differentiated adipocytes were incubated with different concentrations of PDE inhibitors and glycerol release was measured as index of lipolysis. Amrinone at $100 \mu \mathrm{M}$ significantly increased isoproterenol-induced (but not basal) lipolysis $(\mathrm{p}<0.05)$. Cilostamide at concentration of $100 \mu \mathrm{M}$ significantly increased basal lipolysis from $100 \pm 7 \%$ to $334 \pm 24 \%(\mathrm{p}<0.001)$ and also enhanced stimulated lipolysis from $375 \pm 48 \%$ to $668 \pm 34 \%$ ( $\mathrm{p}<$ 0.01 ) (Figure 6A). At the concentration of 10 and $100 \mu \mathrm{M}$, basal lipolysis was not changed by MC2. However, it significantly decreased isoproterenol-induced lipolysis from $374 \pm 48$ to $225 \pm 27 \%(\mathrm{p}<0.01)$ at $100 \mu \mathrm{M}$ (Figure 6B).

\section{Discussion}

The PDEs play an important role in endocrine and cardiovascular functions, cell proliferation, cell differentiation, inflammation, and oxidative stress. Therapeutic application of PDE inhibitors, therefore, ranges from heart failure to pulmonary diseases to erectile dysfunction [31,32]. However, clinical application of these agents is limited because of their side effects, such as arrhythmia, impaired insulin secretion, and alterations in lipid metabolism [4,7]. Therefore, synthesis of new PDE3 inhibitors with desired pharmacological properties and lesser side effects is of great interest. In our previous work, we synthesized MC2 as a new cilostamide derivative and showed that it has inotropic action without unwanted effect on contraction rate $[11,13]$. In the present work, to assess the effect of synthesized compound on lipid metabolism, we investigated its effects on adipose tissue functions. Our data showed that MC2 unlike
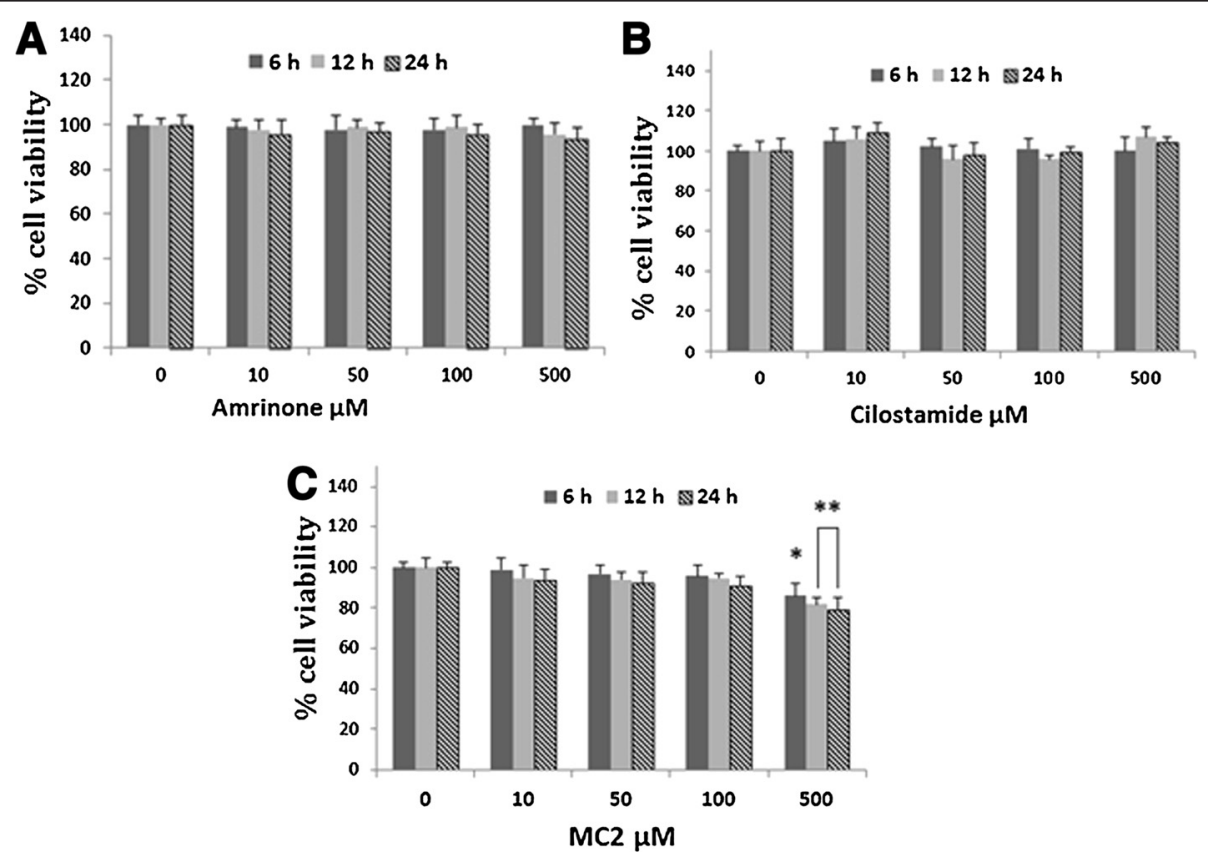

Figure 4 Effects of phosphodiestrase inhibitors on viability of differentiated adipocytes. The cells were incubated with various concentrations of amrinone (A), cilostamide (B) and MC2 (C) for 6, 12 or 24 h. Cell viability was detected using MTT colorimetric assay. Values are mean \pm SEM $(n=9)$. ${ }^{*} p<0.05$ and ${ }^{* *} p<0.01$ vs control cells $(0 \mu M)$. 

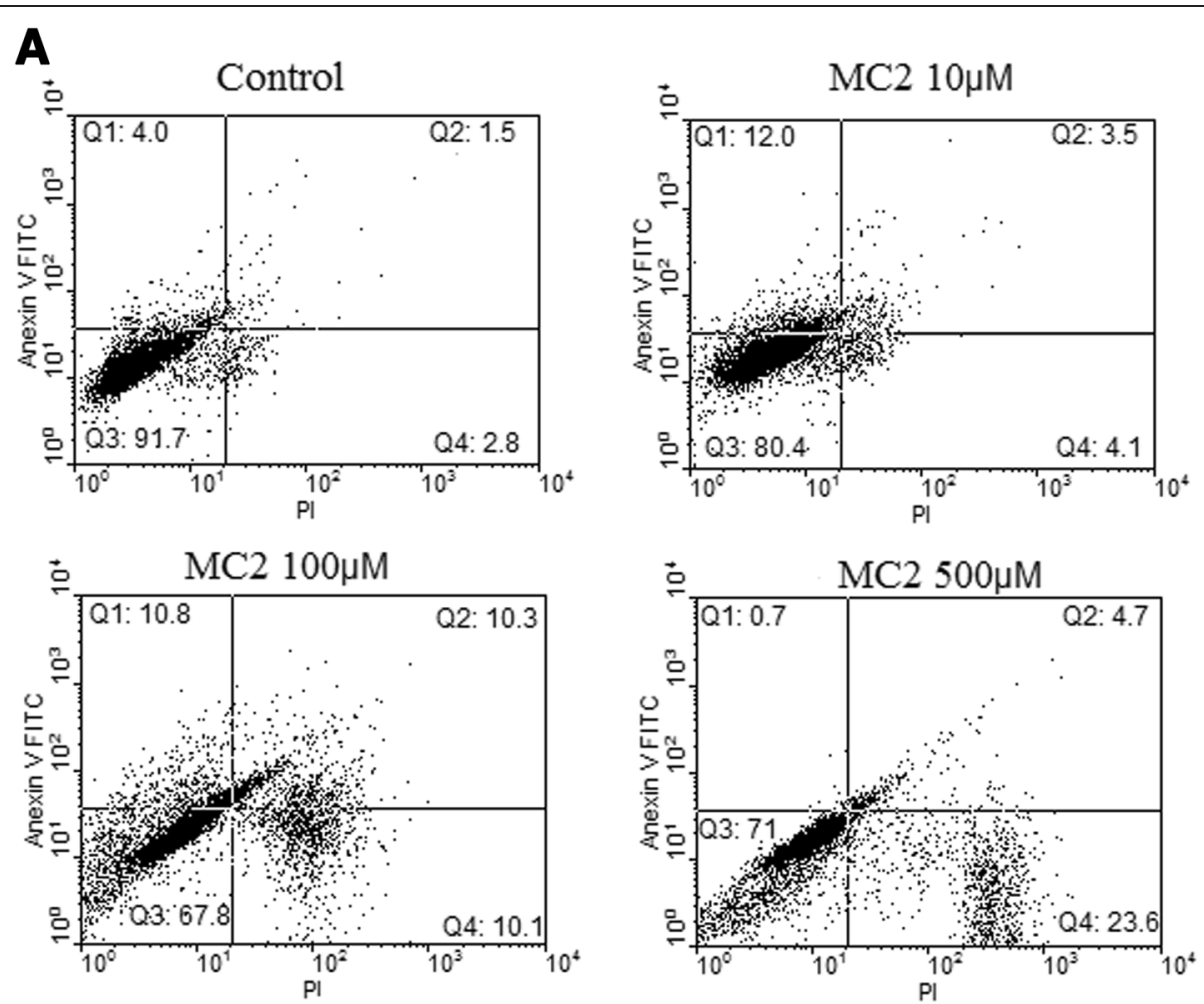

B

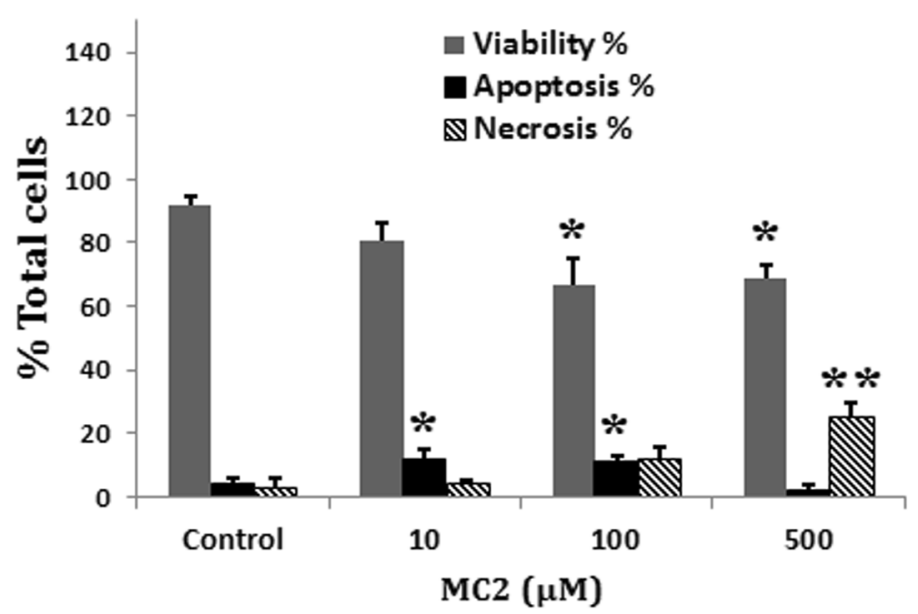

Figure 5 Effect of MC2 on apoptosis of adipocyte. (A) Detection of apoptosis and necrosis assessed with annexin-V-FITC and PI staining. The cells were treated with the indicated concentration of MC2 for $24 \mathrm{~h}$. (B) Column bar graph of mean cell florescence for Annexin V-/Pl- (Viable cells), Annexin V+/PI- (apoptotic cells), Annexin V+/PI+ (necrotic cells). Data are mean \pm SEM of three experiments. ${ }^{*} p<0.05$ and ${ }^{* *} p<0.01$ vs control.

other PDE3 inhibitors does not increase adipogenesis and lipolysis and even has antilipolytic effect.

In agreement with previous reports, in our study the PDE3 inhibitors amrinone and cilostamide potentiated both basal and catecholamine (isoproterenol)-stimulated glycerol release from adipocyte [33]. However, MC2 not only did not increase lipolysis, but inhibited catecholamineinduced glycerol release. Previously, in an in-vitro study we showed that MC2 increases liver glycogen storage in rat and mouse which was different from those of other PDE inhibitors [12]. These effects of MC2 cannot be explained with its PDE3 inhibitory action because PDE inhibitors enhance lipolysis via elevation of intracellular cAMP [2].

In our previous studies we found that different PDE3 inhibitors produce differential cardiac and metabolic effects. All of test compounds produced positive inotropic effect but with different efficacies, which were not 

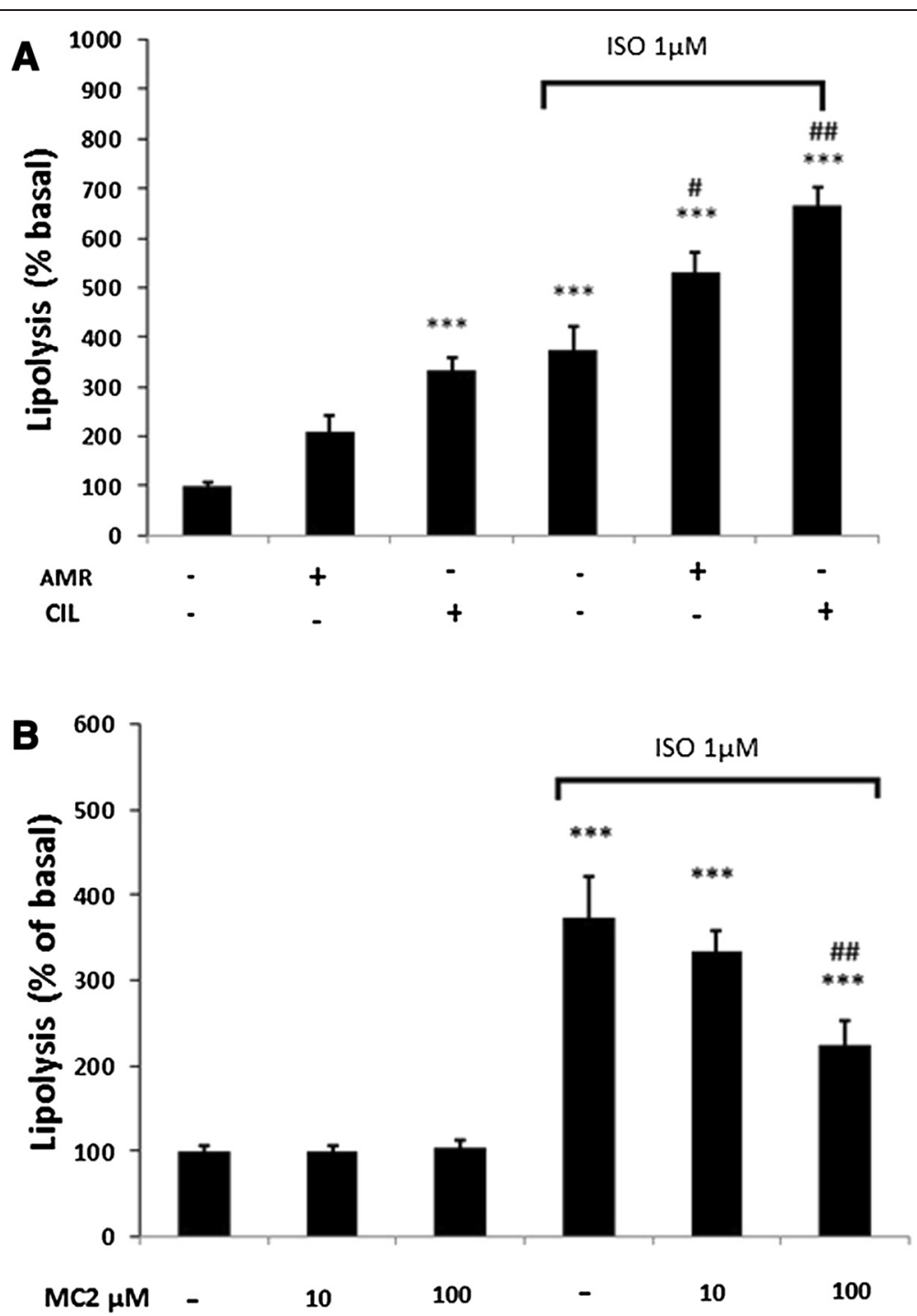

Figure 6 Effects of phosphodiestrase inhibitors on basal and isoproterenol (ISO)-induced lipolysis. Differentiated adipocytes were incubated with $100 \mu \mathrm{M}$ amrinone (AMR), $100 \mu \mathrm{M}$ cilostamide (CIL) (A) or indicated concentration of MC2 (B) for 120 min. Glycerol release in the culture media was assayed as lipolysis indicator. Data are mean \pm SEM of three experiments. ${ }^{*} \mathrm{P}<0.05$ and ${ }^{* * *} \mathrm{P}<0.001$ vs Control; \#p $<0.05$ and $\# \# p<0.01$ vs ISO treated cells.

correlated with their $\mathrm{IC}_{50}$ of PDE3 inhibition. Also, they modified atrial contraction rates differently and some of which produced a negative chronotropic effect in spite of having a high positive inotropic effects [11]. Also, in rat hyperglycemic clamp model MC2 increased insulin secretion similar to the other tested PDE inhibitors, but opposite to others it increased the level of glycogen in the liver [12]. These effects implicate that a cAMP-independent signaling pathways may be involved in the biological effects of PDE inhibitors which is manifested by MC2 and may mediate its antilipolytic effect.
In patients with poorly controlled diabetes, deficiency of insulin in conjunction with catecholamine- and glucagon-stimulated lipolysis enhances fatty acid delivery to liver which may lead to ketoacidosis and even death [19]. It is reasonable to conclude that MC2 can decrease the risk of ketoacidosis through inhibition of lipolysis in diabetic patients who are candidate to PDE inhibitor therapy due to cardiovascular diseases.

Consistent with previous reports on the role of PDE inhibitors in adipogenesis [16,34], we found that deprivation of differentiation medium from IBMX attenuated adipogenesis. Neither cilostamide nor MC2 could restore the level of 
adipocyte differentiation to that of IBMX treated group. It has been revealed that PDEs exist in two forms: soluble (cytosolic) and particulate (membrane-associated) [35]. It is generally accepted that inhibition of soluble but not particulate PDE activity is responsible for IBMXstimulated differentiation of pre-adipocytes [36]. Therefore, inhibition of PDE3 which predominately exist in the form of particulate cannot mimic the role of IBMX in adipocyte differentiation. On the other hand, similar to what happens in the heart and kidney [37], amrinone, in high concentration may inhibit soluble PDE and therefore could induce adipocyte differentiation approximately to the level induced by IBMX.

The mass of adipose tissue is determined by size and number of adipocytes. The size of adipocytes is reduced by lipolysis and increased by lipogenesis $[38,39]$. Number of adipocytes is directly related to the rate of adipogenesis and inversely related to the rate of apoptosis. Results of Annexin V/PI and MTT assays showed that MC2 increases adipocyte apoptosis. However, this effect was produced at high concentrations which reduced cell viability and proliferation. Since MC2 cannot increase adipogenesis, its potential proapoptotic effect may reduce total adipocytes number in fat tissue. However, antilipolytic effect of MC2 may prevent severe alteration in the mass of adipose tissue. Future works are needed to address long term effect of MC2 on fat mass.

In conclusion, our data showed that different types of PDE3 inhibitors induce different effects on lipolysis and adipogenesis. Here we introduced $\mathrm{MC} 2$ as a new PDE3 inhibitor with potential proapoptotic and antilipolytic effects on adipocytes and without stimulatory action on adipogenesis. These effects of MC2 implicate that, in comparison with amrinone or milrinone, this drug may have lowest metabolic side effect and might be a good candidate for treatment of congestive heart failure.

\section{Competing interests}

The authors declare that they have no competing interests.

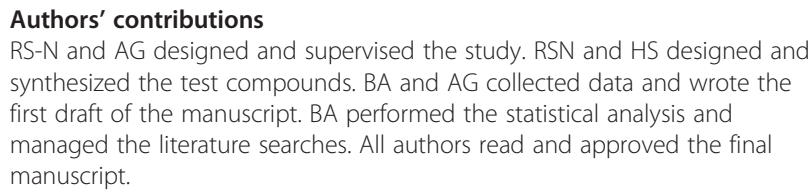

\section{Acknowledgments}

This work was a part of the Ph.D. thesis of one of the authors (Bagher Alinejad) and supported by a grant from Research Council of Mashhad University of Medical Sciences, Mashhad, Iran

\footnotetext{
Author details

${ }^{1}$ Department of Pharmacology, School of Medicine, Mashhad University of Medical Sciences, Mashhad, Iran. ${ }^{2}$ Pharmacological Research Center of Medicinal Plants, School of Medicine, Mashhad University of Medical Sciences, Mashhad, Iran. ${ }^{3}$ Department of laboratory Sciences, School of Paramedical Sciences, Mashhad University of Medical Sciences, Mashhad, Iran.
}

Received: 14 May 2014 Accepted: 5 February 2015

Published online: 21 February 2015

\section{References}

1. Francis SH, Turko IV, Corbin JD. Cyclic nucleotide phosphodiesterases: relating structure and function. Prog Nucleic Acid Res Mol Biol. 2001:65:1-52.

2. Snyder BP, Esselstyn JM, Loughney K, Wolda SL, Florio VA. The role of cyclic nucleotide phosphodiesterases in the regulation of adipocyte lipolysis. J Lipid Res. 2005;46:494-503.

3. Palmer D, Maurice $\mathrm{DH}$. Dual expression and differential regulation of phosphodiesterase $3 \mathrm{~A}$ and phosphodiesterase $3 \mathrm{~B}$ in human vascular smooth muscle: implications for phosphodiesterase 3 inhibition in human cardiovascular tissues. Mol Pharmacol. 2000;58:247-52.

4. Degerman E, Ahmad F, Chung YW, Guirguis E, Omar B, Stenson L, et al. From PDE3B to the regulation of energy homeostasis. Curr Opin Pharmacol. 2011;11:676-82.

5. Liu H, Maurice DH. Expression of cyclic GMP-inhibited phosphodiesterases $3 A$ and $3 B$ (PDE3A and PDE3B) in rat tissues: Differential subcellular localization and regulated expression by cyclic AMP. Br J Pharmacol. 1998;125:1501-10.

6. Hall IP. Isoenzyme selective phosphodiesterase inhibitors: potential clinical uses. Br J Clin Pharmacol. 1993:35:1-7.

7. Movsesian M, Wever-Pinzon O, Vandeput F. PDE3 inhibition in dilated cardiomyopathy. Curr Opin Pharmacol. 2011;11:707-13.

8. Boswell-Smith V, Spina D, Page CP. Phosphodiesterase inhibitors. Br J Pharmacol. 2006;147:S252-7.

9. Curfman GD. Inotropic therapy for heart failure-an unfulfilled promise. New Engl J Med. 1991;325:1509-60.

10. Smith AH, Owen J, Borgman KY, Fish FA, Kannankeril PJ. Relation of milrinone after surgery for congenital heart disease to significant postoperative tachyarrhythmias. Am J Cardiol. 2011;108:1620-4.

11. Hosseini A, Shafiee-Nick R, Parsaee H, Sadeghian H. Inotropic and chronotropic effects of new cilostamide derivatives on isolated rat atria. Iran J Physiol Pharmacol. 2011;15:341-50.

12. Hosseini A, Shafiee-Nick R, Pour Ali Behzad N, Sadeghian H. Differential metabolic effects of novel cilostamide analogs, methyl carbostiryl derivatives, in mouse and hyperglycemic rat. Iran J Basic Med Sci. 2012;15:916-25.

13. Mansouri SM, Shafiee-Nick R, Parsaee $H$, Seyedi SM, Saberi MR, Sadeghian $H$. Inotropic and chronotropic effects of 6-hydroxy-4-methylquinolin-2(1H)-one derivatives in isolated rat atria. Iran Biomed J. 2008;12:77-84.

14. Sadeghian H, Seyedi SM, Saberi MR, Nick RS, Hosseini A, Bakavoli M, et al. Design, synthesis and pharmacological evaluation of 6-hydroxy-4methylquinolin-2 (1H)-one derivatives as inotropic agents. J Enzyme Inhib Med Chem. 2008;24:918-29.

15. Chaves VE, Frasson D, Kawashita NH. Several agents and pathways regulate lipolysis in adipocytes. Biochimie. 2011;93:1631-40.

16. Jia B, Madsen L, Petersen RK, Techer N, Kopperud R. Activation of Protein kinase $A$ and exchange protein directly activated by CAMP promotes adipocyte differentiation of human mesenchymal stem cells. PLoS One. 2012;7:e34114

17. Arner P, Langin D. Lipolysis in lipid turnover, cancer cachexia, and obesityinduced insulin resistance. Trends Endocrinol Metab. 2014;25:255-62.

18. Fabbrini E, Mohammed BS, Magkos F, Korenblat KM, Patterson BW, Klein S Alterations in adipose tissue and hepatic lipid kinetics in obese men and women with nonalcoholic fatty liver disease. Gastroenterology. 2008;134:424-31.

19. Perilli G, Saraceni C, Daniels MN, Ahmad A. Diabetic ketoacidosis: a review and update. Curr Emerg Hosp Med Rep. 2013;1:10-7.

20. Degerman E, Belfrage P, Newman AH, Rice KC, Manganiello VC. Purification of the putative hormone-sensitive cyclic AMP phosphodiesterase from rat adipose tissue using a derivative of cilostamide as a novel affinity ligand. J Biol Chem. 1987:262:5797-807.

21. Ghorbani A, Hadjzadeh MR, Rajaei Z, Zendehbad SB. Effects of fenugreek seeds on adipogenesis and lipolysis in normal and diabetic rat. Pakistan J Biol Sci. 2014;17:523-8.

22. Ghorbani A, Feizpour A, Hashemzahi M, Gholami L, Hosseini M, Soukhtanloo $M$, et al. The effect of adipose derived stromal cells on oxidative stress level, lung emphysema and white blood cells of guinea pigs model of chronic obstructive pulmonary disease. DARU J Pharm Sci. 2014;22:26. 
23. Ghorbani A, Jalali SA, Varedi M. Isolation of adipose tissue mesenchymal stem cells without tissue destruction: a non-enzymatic method. Tissue Cell. 2014;46:54-8.

24. Okazaki H, Igarashi M, Nishi M, Tajima M, Sekiya M, Okazaki S, et al. Identification of a novel member of the carboxylesterase family that hydrolyzes triacylglycerol: a potential role in adipocyte lipolysis. Diabetes. 2006;55:2091-7.

25. Mortazavian SM, Ghorbani A. Antiproliferative effect of viola tricolor on neuroblastoma cells in vitro. Aust J Herbal Med. 2012;24:93-6.

26. Mortazavian SM, Ghorbani A, Hesari TG. Effect of hydro-alcoholic extract of Viola tricolor and its fractions on proliferation of uterine cervix carcinoma cells. Iranian J Obstet Gynecol Infertility. 2012;15:9-16.

27. Forouzanfar F, Goli AA, Assadpour E, Ghorbani A, Sadeghnia HR. Protective effect of Punica granatum L. against serum/glucose deprivation-induced PC12 cells injury. Evid Based Complement Alternat Med. 2013;2013:716730.

28. Vermes I, Haanen C, Steffens-Nakken H, Reutelingsperger C. A novel assay for apoptosis flow cytometric detection of phosphatidylserine expression on early apoptotic cells using fluorescein labelled annexin V. J Immunol Methods. 1995:184:39-51.

29. Ghorbani A, Abedinzade M. Comparison of in vitro and in situ methods for studying lipolysis. ISRN Endocrinol. 2013;2013:205385

30. Ghorbani A, Omrani GH, Hadjzadeh MR, Varedi M. Proinsulin C-peptide inhibits lipolysis in diabetic rat adipose tissue through phosphodiestrase-3B enzyme. Horm Metab Res. 2013;45:221-5.

31. Lugnier C. PDE inhibitors: a new approach to treat metabolic syndrome? Curr Opin Pharmacol. 2011:11:698-706.

32. Rajiv M, Vinod K. Phosphodiesterase inhibitors and their role in therapeutics. J Res Med Educ Ethics. 2013:3:115-23.

33. Ghorbani A, Omrani GH, Hadjzadeh MR, Varedi M. Effects of rat C-peptide-II on lipolysis and glucose consumption in cultured rat adipose tissue. Exp Clin Endocrinol Diabetes. 2011;119:343-7.

34. Jeon YH, Heo YS, Kim CM, Hyun YL, Lee TG. Phosphodiesterase: overview of protein structures, potential therapeutic applications and recent progress in drug development. Cell Mol Life Sci. 2005;62:1198-220.

35. Elks ML, Manganiello VC. A role for soluble CAMP phosphodiesterases in differentiation of 3 T3-L1 adipocytes. J Cell Physiol. 1985;124:191-8.

36. Sun L, Nicholson AC, Hajjar DP, Gotto Jr AM, Han J. Adipogenic differentiating agents regulate expression of fatty acid binding protein and CD36 in the J744 macrophage cell line. J Lipid Res. 2003:44:1877-86.

37. Ghosh R, Sawant O, Ganpathy P, Pitre S, Kadam V. Phosphodiesterase inhibitors: their role and implications. 2009;1:1148-1160

38. Rayalam S, Della-Fera MA, Baile CA. Phytochemicals and regulation of the adipocyte life cycle. J Nutr Biochem. 2008;19:717-26.

39. Ghorbani A, Varedi M, Hadjzadeh MR, Omrani GH. Type-1 diabetes induces depot-specific alterations in adipocyte diameter and mass of adipose tissues in the rat. Exp Clin Endocrinol Diabetes. 2010;118:442-8.

\section{Submit your next manuscript to BioMed Central and take full advantage of:}

- Convenient online submission

- Thorough peer review

- No space constraints or color figure charges

- Immediate publication on acceptance

- Inclusion in PubMed, CAS, Scopus and Google Scholar

- Research which is freely available for redistribution 